\title{
Milton Rossel
}

\section{Pio Baroja}

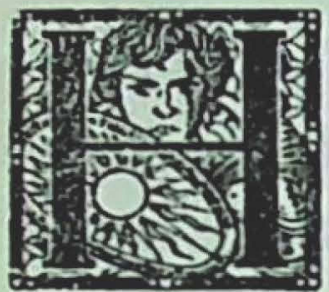

ACER la necrología de Pío Baroja es en cierto modo traicionar su memoria, porque para él no caben las palabras del registro usual con que expresamos un sentimiento de dolor. Para él tampoco el recogimiento meditativo con la intención de hacer filosofía doméstica sobre la caducidad de las cosas terrenales. Se caería, si deploramos de esta manera su muerte, en tópicos, en moldes consabidos, en palabras de circunstancias muy distantes del hombre y del escritor que huyó de ripios y lugares comunes.

Hablar de Pío Baroja implica fundir en un mismo plano al autor y su obra, y nada se puede decir sobre el uno y la otra que no haya sido dicho por el propio escritor. Casi toda su abundante labor literaria tiene carácter autobiográfico como que los principales personajes de su mundo novelesco están trazados con rasgos psíquicos en que es fácil descubrir la identidad del progenitor. Además, en varios de sus libros, en prólogos de sus novelas y especialmente en sus memorias, se preocupó de hablar de sí mismo. Se encargó de darse a conocer desnudamente, de definirse sin piedad, de exhibir sin tapujos su condición de hombre rebelde e insobornable.

La bibliografía del escritor vasco es extensa y copiosa, y sus admiradores son tan abundantes como sus detractores. Un estudio, pues, 
sobre Baroja y su obra, exige la reproducción de largas acotaciones a juicios en que se le examina desde los más opuestos ángulos. Remitirse a lo que sobre él se ha escrito es reconocer el fracaso de su lección en quien ha sido entusiasta y asiduo lector suyo. Por eso preferimos la reacción personal a través de los residuos emotivos que fueron dejando la lectura de sus libros, y subrayar su poderosa influencia hasta considerar nuestras actitudes en ciertos casos como las de un personaje barojiano.

En pleno hervor de la adolescencia iniciamos la lectura del autor de La Busca. No nos fué grata la iniciación. Nos pareció desabrido, seco, sin gracia, desprovisto de ese léxico y de esa fraseología que tanto gusta cuando se presume ya de hombre para exhibirla como propia en discursos o en conversaciones. Baroja desentonaba en medio de la orquestación verbal del modernismo que todavía en nuestros años de liceano se imponía como la más definitiva expresión de la audacia literaria. Por eso nos atraía más la lectura de Valle-Inclán con sus epítetos inauditos y sus juegos de artificio, o la de José Enrique Rodó con sus severos períodos de entonación oratoria. Pero teníamos que leer a Baroja. Nos lo había exaltado en sus clases de castellano don Enrique Marshall, cuyas opiniones en materias literarias acatábamos. Así, cada cierto tiempo y en forma constante leímos libros de Baroja. Poco a poco nos fué captando el tono romántico, desvaído, con que pintaba el paisaje; sus personajes audaces, aventureros, huraños, inconformistas; y finalmente su rotunda sinceridad para referirse a hombres y cosas. De este modo Baroja pasó a ser uno de nuestros escritores favoritos, preferentemente sus libros autobiográficos, porque en ellos encontramos lo más genuino de su personalidad, su insubordinación contra todo lo consagrado, contra las normas convencionales de la sociedad, contra los políticos falaces, contra los de estilo académico, elocuentes y solemnes; intransigente con la crueldad y la estupidez humanas. Lo hemos leído casi ininterrumpidamente, incluso releído con ocasión de su muerte, para rectificar o ratificar la opinión que acerca de alguna obra suya teníamos. Casi siempre la refirmamos en sentido favorable. 
Hay que aprender a gustar a Baroja como se aprenden a gustar esos platos cuyo sabor rechaza el paladar por no estar acostumbrados a ellos. Aparentemente Baroja es un escritor fácil. Pero su lectura requiere un abono previo, o mejor, desbrozar el espíritu de todo lo que nos ha quedado de la tradición literaria española, a fin de penetrar en el sentido profundamente humano de su enfoque de la vida, en su filosofía sacada del tráfago cotidiano, dicha en forma inusitada por su decantación verbal. Cada novela de Baroja fué dejando un sedimento de amargura que en los años de inconformismo nos servía para justificar nuestra propia rebeldía e inadaptación. A Baroja sólo lo podrá apreciar el que se siente barojiano.

Su estilo preciso, sobrio, conversacional, sus frases llanas sin el menor artificio, sus relatos desarticulados, la sinceridad de sus juicios, el dinamismo de los hechos novelados, todo ello fué atrayéndonos hasta el punto de considerar la lectura de Baroja como una necesidad para desintoxicarse del retoricismo amanerado, de los lugares comunes y de todo ese plebeyismo intelectual a que nos ha conducido un errado concepto de la democracia, de nivelar por lo bajo.

Una vez que se logra entrar en el mundo barojiano es difícil salir de él. Posee un misterioso poder de seducción. Un algo que coge y retiene como esos seres que en la multitud de desconocidos destacan por su actitud silenciosa y huraña, oportunos y agudos en sus observaciones, irónicos con aquellos que lo hablan todo, escuchándose a sí mismos. Son seres escasos y desconcertantes. Generalmente solitarios, que no despiertan simpatía a primera vista. Así, Baroja. Por eso no fué un escritor popular si bien sus obras han tenido en Hispanoamérica gran difusión. Nada hay en él para las mayorías indiferenciadas o para el seudointelectual que va tras lo trascendente y metafísico. Lo rechazan generalmente los profesores de gramática y retórica, los académicos de antiguo cuño, los oradores que transpiran después de cada período. Tampoco Baroja podrá ser del agrado de los editorialistas sesudos y patéticos, y menos de los fanáticos de la derecha o de la izquierda, de esos que viven aprisionados por dogmas y consignas. 
Se ha hablado mucho del anarquismo de Baroja, de su individualismo cerrado, de su antiacademicismo, de su anticlericalismo, de su humorismo incisivo, de su nietzscheanismo. Repetir tales conceptos sería caer en una actitud antibarojiana de aceptar la opinión consagrada en textos o memorias para optar a título universitario. Creemos que Baroja no se trazó jamás en su larga existencia una norma ni una línea de conducta, ni como hombre ni como escritor. Todo en él fué reacción personal y espontánea, impulso de su temperamento rico y variado, curioso, inquieto, sedentario, vagabundo, cerebral, sentimental, solitario, huraño, amable, en permanente rebeldía frente a todo lo que limitara su naturaleza psicológica. Por eso resulta absurdo someterlo a una medida y juzgarlo desde un solo ángulo. Acomodó su vida y su palabra a su índole. Nada lo limitó ni pretendió difundir nada, aunque su formación filosófica y literaria tiene claros antecedentes en Kant, Schopenhauer, Nietzsche, Dostoiewski, Dickens, Stendhal, autores que declaró varias veces haber admirado.

Noveló Baroja los hechos cotidianos y las circunstancias de la realidad en que vivió. Se nutrió del tumulto de la vida. A pintar seres acartonados, prefirió novelar la vida de vagabundos, aventureros, caminantes, mendigos, bohemios, labriegos, anarquistas, guerrilleros, tipos populares, con algo de primitivo. Al hombre engolado y presumido, prefirió el individuo modesto y humilde; al burgués anodino, el inquieto y trashumante, inadaptado al medio; al intelectual arrivista, el disociador de ideas y principios. Los pintó con humana simpatía. En cambio fué duro, violento, agresivo con los políticos inescrupulosos, con los especuladores, con los sinvergüenzas. Jamás transigió con la mentira, el engaño, la estulticia. No fué un escéptico que se sonriera irónicamente ante el espectáculo de miseria que ofrece el mundo. Su visión de la vida fué pesimista, del desengañado que tras mucho observar y analizar llega a la conclusión de que el hombre sigue siendo enemigo del hombre. Pero no fué patético ni estridente en su protesta contra la sociedad dominada por la injusticia. Se limitó a pintarla crudamente con los tonos sombríos del desengaño. No olvidemos que Baroja pertenece a la generación del desastre, que surge 
a las letras el año 1898, cuando España llega a la culminación de su decadencia política.

Se ha dicho que Baroja era descuidado para escribir, que atropellaba a veces las reglas gramaticales, que su prosa es fría, antipoética. Indudablemente no se preocupó de pulir ni retocar la expresión. Por el contrario, huía de los períodos rotundos, de los adornos literarios, de todo lo que fuera afectación y relleno. Trató de ser claro, sobrio, directo, a fin de llegar al lector con el mínimo de palabras y sin interferencias literarias que impidieran el conocimiento inmediato de lo que decía. Pero ello no significa que Baroja no tuviera estilo. Precisamente en esa ausencia de adornos, en su sencillez y espontaneidad para decir las cosas, reside su personalidad de escritor, inconfundible, única en la literatura española. Para él lo fundamental era la vida, contar hechos, transmitir emociones. Los adornos le parecían algo superfluo, simple retórica para ocultar la pobreza de contenido humano y esencial. Tal estilo desprovisto de "literatura" le permitió escribir páginas hermosísimas, impregnadas de auténtica poesía, que él mismo se encargó de antologar en Páginas Escogidas. Recordamos "El elogio sentimental del acordeón", numerosos retratos y escenas populares, descripciones de lugares de España o de ciudades como $\mathrm{Pa}$ rís, Roma, Londres. Su estilo escueto, breve, sugerente, es de gran plasticidad evocadora.

Novelista, memorialista, ensayista, Pío Baroja fué una figura singular en el mundo literario de la España contemporánea. Heredero de la tradición novelística de Galdós, en su obra múltiple están vivas las almas y las inquietudes de un pueblo que se agita en constante estado de lucha contra su sino histórico y que aun en la adversidad y la derrota se yergue viril, enhiesto y rebelde como lo fué Pío Baroja hasta los últimos días de su larga existencia.

Para el autor de Vidas sombrías, Camino de perfección, La busca, Aurora roja, Las inquietudes de Santhi-Andía, El mundo es ansi, El árbol de la ciencia, Juventud, egolatría, Las horas solitarias, El mayorazgo de Labraz, un recuerdo de gratitud por su lección de rebeldía y de humanidad. 